\title{
Sexual Aversion Disorder
}

National Cancer Institute

\section{Source}

National Cancer Institute. Sexual Aversion Disorder. NCI Thesaurus. Code C94338.

A disorder characterized by recurrent or persistent extreme aversion to, and avoidance of, all genital contact with a sexual partner. The aversion to sexual contact is not attributable to another psychiatric disorder. 